\title{
François Jacob y la integración de biología, filosofía y antropología
}

\author{
Sergio Alcántara Ferrer
}

En este ensayo sobre el libro de François Jacob, El juego de lo posible, se analizan sus aportaciones en cuanto a la relación entre mito y ciencia, el papel de la genética molecular en la selección natural y el paso de la evolución biológica a la cultural, incorporando el tema del tiempo y la capacidad de proyección de la conciencia hacia el futuro. El autor de este ensayo-comentario pondera el contenido del libro entretejiéndolo con las aportaciones al respecto de diversos antropólogos culturales clásicos. El resultado es un llamado a la reflexión sobre la solidez del método científico en antropología, a pesar de algunas tendencias recientes en contrario.

PALABRAS CLAVE: ciencia versus mito, evolución, bioquímica, cultura, endoculturación

\section{François Jacob and the Integration of Biology, Philosophy and Anthropology}

This essay analyses the contributions made by François Jacob in the book The Possible \& the Actual, regarding the relationship between myth and science, the role of molecular genetics in natural selection, and the transition from biological to cultural evolution, including the topics of time and the capability of projecting consciousness towards the future. The author of this essay/commentary reflects on the contents of Jacob's book, and intertwines them with the contributions of several classic cultural anthropologists. The result is an invitation to reflect on the soundness of the scientific method in anthropology, regardless of some recent currents that claim the opposite.

KEY WORDS: science versus myth, evolution, biochemistry, culture, endoculturation

SERGio AlCÁNTARA FERrer: El Colegio de Jalisco, Jalisco, México.

saferrer@prodigy.net.mx 
$\mathrm{N}$ o es muy común encontrar un libro de ensayos en el campo de las ciencias que sea breve $y$, sin embargo, que su contenido constituya una verdadera aportación al pensamiento racional, que suscite ideas interesantes a la vez que le permita al lector seguir planteándose incógnitas pertinentes. El magnífico libro del biólogo francés, Premio Nobel de Medicina, François Jacob, El juego de lo posible, cumple plenamente con esas características ${ }^{1}$.

El libro se compone de un prólogo breve y tres artículos de fondo titulados "Mito y ciencia", "El bricolage de la evolución" y "El tiempo y la invención del porvenir". Antonio Velázquez Arellano, del Instituto de Investigaciones Biomédicas de la Universidad Nacional Autónoma de México (UNAM), tuvo a su cargo la presentación de la obra. En su texto, Velázquez Arellano pondera como enigmas las tres ideas centrales que Jacob elabora en su libro: "el desarrollo de la vida en la Tierra,[...] el desarrollo de un complejo organismo adulto a partir de una célula, y la conciencia de uno mismo, de nuestra finitud y el transcurrir del tiempo y del Universo" (p. 11). Señala luego el destacado papel que François Jacob ha tenido en la develación de los problemas relacionados con el origen biológico del ser humano y su evolución, sobre todo en la segunda parte del siglo XX. Notable sobre todo fue el descubrimiento que, junto con Jacques Monod, hiciera Jacob sobre el funcionamiento del genoma. Velázquez subraya también el papel profético de Jacob cuando planteó que es necesario entender primero el desarrollo embrionario a fin de comprender el proceso de evolución biológica (p. 13). Velázquez termina su presentación con una breve síntesis de la trayectoria académica de Jacob, la cual culminó con la obtención del Premio Nobel de Medicina en 1965.

En su "Prólogo", Jacob plantea de manera escueta y lúcida el objetivo principal de su libro: mostrar el papel de la ciencia como instrumento para explicar los fenómenos de la realidad, esto es, del mundo concreto en el que se encuentra el ser humano. En otras palabras, jugar con la posibilidad de acercarse a la verdad, pero no a una

${ }^{1}$ François Jacob, El juego de lo posible, Fondo de Cultura Económica, México, 2005 [1ª ed. en francés en 1981]. verdad absoluta sino a una verdad relativa, lo cual es propio de la actividad científica. Jacob destaca el hecho de que un número creciente de seres humanos se haya logrado desprender de la tendencia tan marcada a encerrarse en lo absoluto y en lo definitivo, y optar por la labor de investigación en vez de quedarse atenidos a la revelación como única forma de conocimiento. No obstante, Jacob nos recuerda que: "Pocas personas aceptan que la vida y el hombre se hayan convertido en objetos de investigación y ya no sean objeto de revelación" (p. 18).

Enseguida refuta las acusaciones que suelen hacerse a los científicos por una supuesta falta de conciencia sobre las consecuencias de sus descubrimientos, y explica que "las catástrofes de la historia se deben menos a los científicos que a los sacerdotes y los políticos" (p. 19).

\section{CIENCIA VERSUS MITO}

En el primer capítulo de su muy provechoso libro, Jacob hace una comparación crítica entre mito y ciencia. Por un lado elabora una crítica profunda y acertada sobre el mito; por el otro, al contrario, un elogio también muy acertado de la ciencia. Esta comparación resulta ser oportuna dada la tendencia periódica de algunos investigadores a olvidarse de la ciencia en sus indagaciones sobre los fenómenos de la realidad, y a dejarse llevar por las alucinaciones del mito. Jacob llama la atención de manera contundente sobre ese riesgo. Sin embargo, se advierte un cierto problema de interpretación cuando Jacob tiende a atribuirle al mito casi todas las actividades humanas que no tienen relación directa con la ciencia. Aparentemente, considera que las tradiciones y costumbres de los pueblos son mitos y, por lo tanto, actividades un tanto irracionales o, por lo menos, así lo da a entender.

Por otra parte y, en oposición al mito, Jacob elogia insistentemente a la ciencia, tanto que da por hecho que el científico (de ciencias naturales) se retira del mundo al que trata de estudiar (lo cual es cierto y metodológicamente necesario) y se sitúa "en la posición de un espectador que no forma parte del mundo estudiado. Con esta estrategia, el científico intenta analizar lo que considera que es 'el mundo real de su alrededor'” (p. 31). Este plan- 


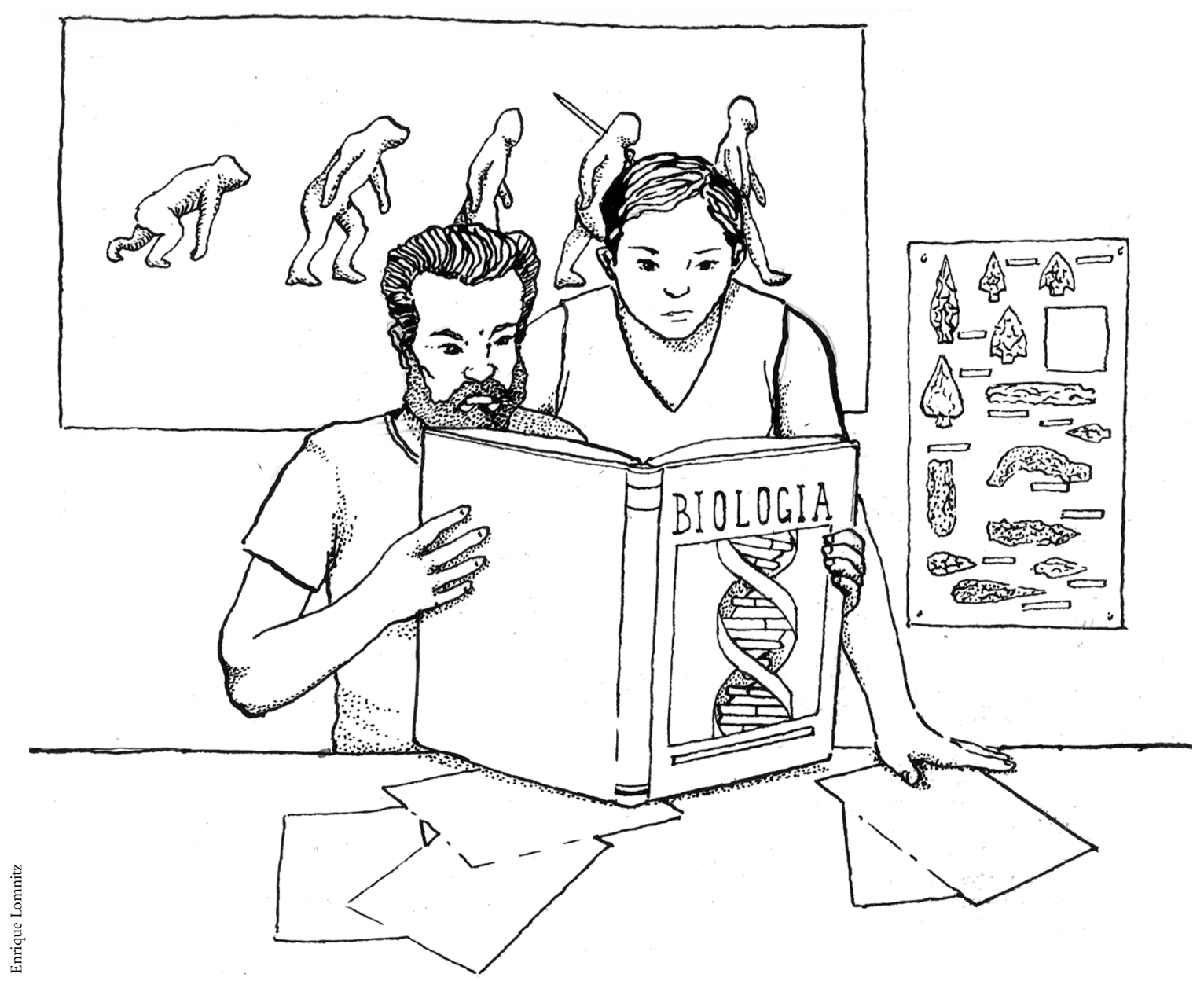

teamiento suscita una pregunta que viene a la mente de inmediato: ¿es eso posible? Aun en ciencias naturales, donde sin duda el científico dispone de mayor libertad metodológica que el científico social, ¿hasta dónde o hasta qué grado puede el hombre de ciencia eludir su responsabilidad social por su acceso al conocimiento y a la información? Podría considerarse que Jacob no elude en efecto esa responsabilidad, ya que se refiere a la separación del investigador en relación con su objeto de estudio tan sólo como una estrategia para intentar analizar el mundo que le rodea.

En su análisis comparativo de la ciencia y el mito, Jacob acude a la evolución biológica como ejemplo de una sólida explicación científica, pero advierte acertadamente sobre el riesgo de abusar de una teoría para acercarse al mito. Al respecto, Jacob considera que "el Universo no se explica en todos sus detalles por una única fórmula o por una sola teoría” (p. 42). Agrega que una teoría como la de la evolución elaborada por Darwin "no podía escapar de un uso abusivo" por parte de grupos de intereses opuestos y, por lo mismo, dicha teoría "es tratada a menudo como un mito” (p. 43). La explicación radica en la posibilidad de que toda sociedad acuda a los mitos para fortalecer su identidad cultural. Sin embargo, Jacob aclara que

[...] un mito contiene una suerte de explicación universal que da a la vida humana sentido y valores morales. Nada indica [sin embargo] que la teoría de la evolución pueda desempeñar tal papel a pesar de las numerosas tentativas realizadas al respecto (p. 44). 
Esta aclaración resulta importante a fin de apreciar mejor el análisis del proceso de evolución biológica que hace Jacob inmediatamente después y con el cual da respuesta a incógnitas que él plantea sobre la relación entre ciencia y mito: “¿Es posible que una historia de los orígenes funcione a la vez como teoría científica y como mito?" (p. 45).

\section{GENÉTICAY EVOLUCIÓN BIOLÓGICA HUMANA}

En el segundo ensayo, titulado "El bricolage de la evolución", Jacob se refiere fundamentalmente al componente químico del organismo humano y su importancia en el proceso de evolución biológica del Homo sapiens. Su planteamiento es muy interesante y sumamente rico en el manejo de ideas y juicios sobre la complejidad orgánica del ser humano. Sin embargo, lo hace con tal sapiencia y rigor lógico que en realidad aporta una explicación precisa y clara sobre el tema. Jacob parte de describir la ra de una célula, y cómo en cada uno de esos niveles se lleva a cabo la integración de sus ingredientes, además de la manera como se relacionan los niveles entre sí. Vale la pena transcribir el párrafo en que lo explica, dada la lucidez con que lo hace:

En nuestro Universo la materia es distribuida según una jerarquía de estructuras por una serie de integraciones sucesivas. Ya sean inanimados o vivos, los objetos terrestres forman siempre organizaciones, sistemas. En cada nivel, esos sistemas utilizan como ingredientes algunos de los sistemas de nivel inferior, pero sólo algunos. Las moléculas, por ejemplo, están hechas de átomos, pero las moléculas naturales o las producidas en el laboratorio no representan más que una fracción de todas las interacciones posibles entre átomos. Al mismo tiempo, las moléculas pueden presentar ciertas propiedades, tales como la isomerización o la racernización, que no existen en los átomos. En el nivel superior, las células están hechas de moléculas. Aquí, incluso el conjunto de moléculas de los seres vivos no representa más que una elección muy restringida entre los objetos de la química. Además, las células son capaces de dividirse, pero no las moléculas. En el nivel siguiente, el número de especies animales vivas se eleva a algunos millo-

nes, lo cual es poco en relación con lo que podría ser. Todos los vertebrados están compuestos de ciertos tipos celulares - nervioso, glandular, muscular, etc. - en número limitado, doscientos quizá. Lo que da a los vertebrados su gran diversidad es el número total de células así como la repartición y las proporciones relativas de esos tipos celulares (p. 51).

Del análisis de las estructuras, Jacob pasa al de los procesos de evolución. Explica entonces que la complejidad de los objetos tiene una jerarquía con dos características: 1) los objetos de un determinado nivel sólo constituyen una forma de combinación posible "del nivel más simple", y 2) "en cada nivel pueden aparecer propiedades nuevas que imponen nuevos condicionamientos al sistema" ( $\mathrm{p}$. 52). En otras palabras, cada nivel tiene la posibilidad de cambiar, de manera evolucionada y condicionada. Así, Jacob agrega que:

Vivos o no, los objetos complejos son el producto de procesos evolutivos en los que intervienen dos factores: por una parte, los condicionamientos que, en cada nivel, determinan las reglas del juego y marcan los límites de lo posible; por la otra, las circunstancias que rigen el curso verdadero de los eventos y realizan las interacciones entre los sistemas. La combinación de condicionamiento y de historia se da en cada uno de los niveles, pero en proporciones diferentes. Los objetos más simples están sometidos a los condicionamientos más que a la historia. Con el crecimiento de la complejidad aumenta la influencia de la historia (ibid., cursivas mías).

Estos planteamientos de Jacob, que se refieren a la complejidad y evolución de los organismos biológicos, por analogía podrían aportar elementos de juicio para el análisis de las teorías y conceptos relacionados con las ciencias sociales, en particular la antropología, tal como se verá más adelante.

Al señalar la diferencia de status de la biología con la física, Jacob destaca que:

La explicación en biología tiene un doble carácter. En el estudio de cualquier sistema biológico, en cualquier nivel de complejidad se pueden plantear dos tipos de preguntas: cuál es el funcionamiento y cuál es el origen. La biología experimental se consagra de forma especial, desde hace un siglo, a la primera pregunta, al estudio de las interacciones actua- 
les. Está muy orientada hacia el estudio de los mecanismos y ha proporcionado un cierto número de respuestas en términos fisiológicos, bioquímicos o moleculares. Pero la segunda cuestión — la de la evolución — es quizá la más profunda, pues engloba la primera. Sin embargo, casi siempre las respuestas pueden proceder sólo a partir de suposiciones [¿supuestos?] más o menos razonables. La teoría moderna de la evolución ha fundado las reglas de su juego histórico sobre dos condiciones que rigen a los seres vivos: la reproducción y la termodinámica. No obstante, lo importante en la comprensión de algunos aspectos estructurales y funcionales de los seres vivos no son sólo las reglas sino quizá también los detalles del proceso histórico, ya que cada organismo vivo representa hoy en día el último eslabón de una cadena ininterrumpida de unos tres mil millones de años. De hecho, los seres vivos son estructuras históricas. Son, literalmente, creaciones de la historia (p. 53).

La analogía con las sociedades humanas es evidente en cuanto a que pueden trazarse paralelismos importantes, sobre todo porque las sociedades, como los organismos biológicos, son resultado de la historia o de la evolución de la cultura, como lo planteara Gordon Childe con su famosa conclusión de que "el hombre se hace a sí mismo" $(1970)^{2}$.

Cabe aclarar que, desde luego, la analogía organicista no es nada nuevo en ciencias sociales. La diferencia en cuanto a la aplicación de este enfoque de Jacob, en comparación con la analogía que se hacía en el siglo XIX y que, en algunos casos, dio origen al darwinismo social, sobre todo con las tesis de Herbert Spencer, es que el análisis de Jacob no permite derivar conclusiones obsoletas de tipo racial y discriminatorio ya que, por el contrario, fortalece la noción de la unidad de la especie Homo sapiens, tal

\footnotetext{
${ }^{2}$ La cita de Childe se debe a que, a pesar de haber sido superado en cuestiones de detalle por los descubrimientos de arqueólogos posteriores y, obviamente, mucho más recientes, sin embargo, su explicación general sobre la evolución cultural no sólo sigue siendo válida, sino que constituye una de las aportaciones más lúcidas al conocimiento de la cultura y sus procesos de cambio. Así lo reconoció Graham Clark, otro de los arqueólogos eminentes del siglo XX, en su "Prefacio" a la otra obra clásica de Childe, What Happened in History: "Por otro lado, las obras generales en las cuales él [Childe] abrió perspectivas nuevas y, a menudo, vastas, en muchos casos son clásicas ya que recompensan su relectura constante y es probable que retengan su validez en el porvenir por mucho tiempo" (1964: 7, trad. del suscrito al español).
}

como lo han planteado en numerosas ocasiones los antropólogos físicos y, más recientemente, lo han confirmado los geneticistas con sus análisis del ADN (ácido desoxirribonucléico). En este sentido, entonces, no hay contradicción entre ambos enfoques, sino complementariedad ${ }^{3}$.

Otro punto importante de este capítulo de Jacob es que destaca la importancia de la dimensión molecular en el proceso de evolución biológica y no sólo en el desarrollo de los órganos corporales de los individuos miembros de determinadas especies. Jacob da como ejemplo el análisis de la proteína citocromo $c$ :

[...] que ha aportado información sobre uno de los aspectos más fascinantes del desarrollo de la vida sobre la Tierra: la manera como los organismos logran obtener energía, almacenarla y utilizarla (ibid.).

En este caso, la analogía se relaciona con el planteamiento que hiciera hace casi 50 años otro antropólogo clásico, Leslie White, sobre las sociedades humanas entendidas precisamente como organismos que acumulan y consumen energía para poder lograr su supervivencia $(1959 a)^{4}$. Jacob ofrece una explicación detallada sobre la forma de operación del citocromo $c$.

Enseguida, Jacob plantea el tema de las imperfecciones en la evolución biológica a diferencia del desarrollo de la tecnología, en el cual el ingeniero puede inventar máquinas perfectas o que tienden a serlo. Así, dice Jacob refiriéndose a Darwin:

Por el contrario, la evolución está lejos de la perfección, como repitió una y otra vez Darwin, pues toda su teoría es

\footnotetext{
${ }^{3}$ Entre muchos otros, véase al respecto Erickson y Murphy (2003: 7071) y De Waal Malefijt (2001: 117-120).

${ }^{4}$ Las obras de White, a pesar de haber sido escritas en las décadas de 1950 y 1960, continúan siendo también de lectura obligada, ya que sus aportaciones teóricas y conceptuales, como las de otros autores clásicos de la antropología, siguen vigentes. En el caso de White, por su tesis sobre la acumulación de energía como motor de la evolución de la cultura y su definición misma de ésta en un sentido holístico y a partir de la dimensión simbólica, la cual no sólo antecedió los planteamientos posteriores de Clifford Geertz y de algunos de sus seguidores más recientes, sino que lo hizo de manera mucho más lúcida, precisa y concisa. En una palabra, mucho más convincente. Sobre su concepto de cultura, véase White, 1959.
} 


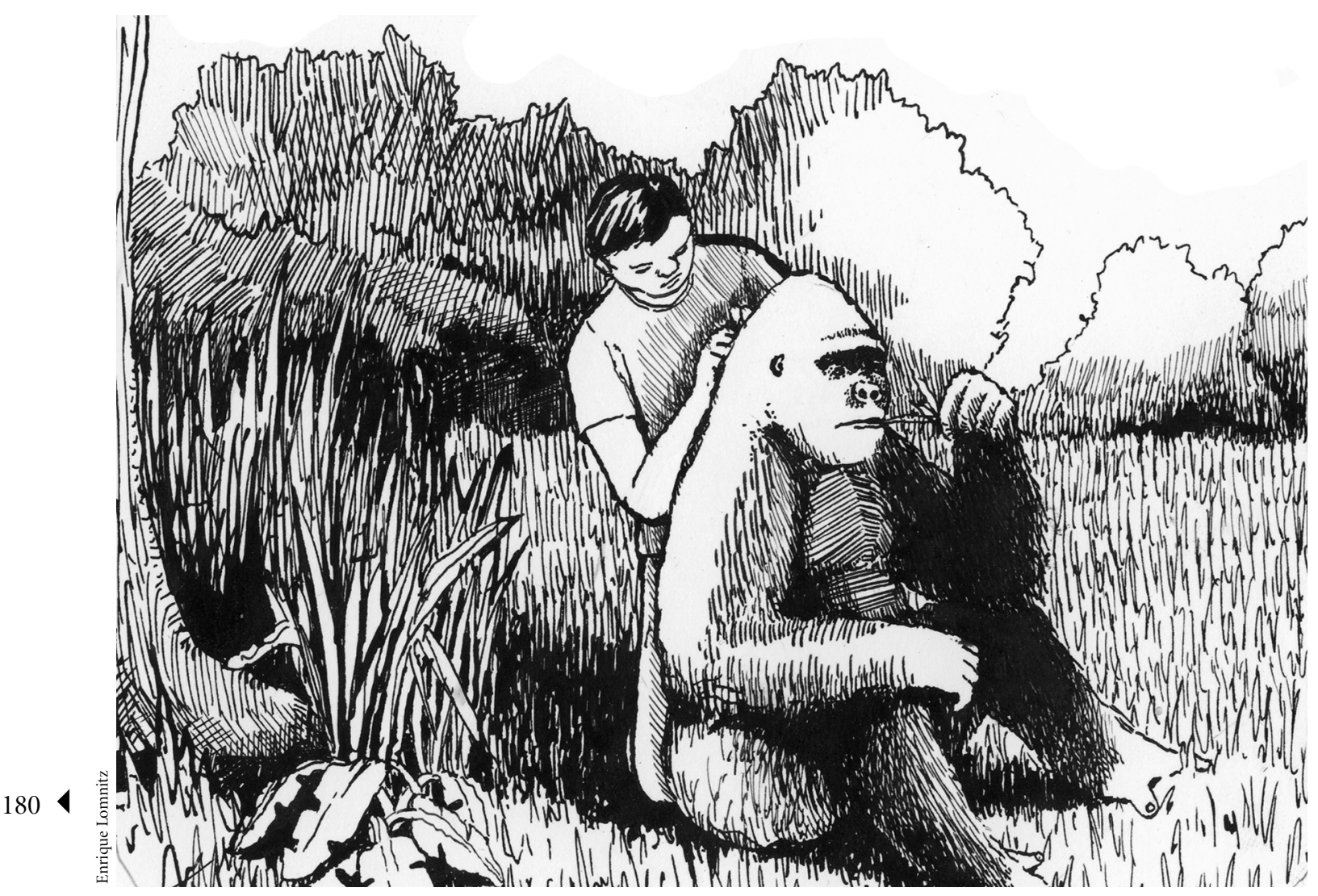

opuesta a la idea de la creación perfecta. A lo largo de El origen de las especies, Darwin insiste en las imperfecciones estructurales y funcionales del mundo vivo. No cesa de subrayar las rarezas, las soluciones extrañas que un Dios racional no hubiera jamás utilizado. Y uno de los mejores argumentos contra la perfección proviene de la extinción de las especies. Se puede estimar en millones el número de especies animales vivas en la actualidad, pero el número de especies que han desaparecido después de haber poblado la Tierra en una época o en otra, según el cálculo de G. C. Simpson, (20) [(20) Simpson, G. C., "How Many Species?", Evolution, 1952, 6, p. 342], se eleva a unos quinientos millones, cuando menos (pp. 55-56).

Esa noción de las imperfecciones podría derivar, en un momento dado, en la idea de la generación de monstruos humanos. Pero, antes, Jacob insiste en su planteamiento de que la evolución biológica procede $\mathrm{u}$ opera a la manera de un bricoleur, término muy francés que en español corresponde a la idea de improvisación. Jacob apli- ca esa noción de improvisación sobre todo en el nivel de las moléculas. $\mathrm{Al}$ respecto, dice lo siguiente:

Quizá sea en el nivel molecular donde se manifiesta con mayor claridad el aspecto bricoleur de la evolución. El mundo viviente se caracteriza, a la vez, por su diversidad visible y su unidad subyacente. Existe una notable unidad de estructura y de función entre organismos tan variados como las bacterias y las ballenas, los virus y los elefantes, los organismos que viven a $-20^{\circ}$ en las regiones polares y aquellos que en superficies calientes viven a $70^{\circ} \mathrm{C}$. Los mismos polímeros, ácidos nucleicos y proteínas, compuestos de los mismos elementos básicos, tienen siempre el mismo papel. El código genético es el mismo y la máquina para traducirlo casi no cambia. Las mismas coenzimas intervienen en reacciones semejantes. De la bacteria al hombre, numerosas reacciones permanecen idénticas (p. 60).

El análisis que hace Jacob de la relación entre la evolución de los componentes químicos celulares con la evo- 
lución genética es fascinante, aunque sumamente compleja para una mente no entrenada en esos campos de la bioquímica. Sin embargo, la racionalidad del análisis jacobiano es muy sugerente para aplicarla al campo de las sociedades humanas y su cultura desde un enfoque antropológico. Precisamente, Jacob llega a hacer un planteamiento a manera de conclusión que resulta útil en la actualidad para contrarrestar, en los planteamientos de la teoría antropológica, la posición de los posmodernistas extremos cuando rechazan el estudio de los clásicos de la antropología y de sus aportaciones teóricas y conceptuales. Jacob concluye en cuanto a la evolución biológica que ésta "se funda, así, en una suerte de bricolage molecular, en la reutilización constante de lo viejo para hacer lo nuevo" (p. 61). En otras palabras, en este campo de la evolución de los organismos biológicos no se descarta lo viejo ni se le considera obsoleto, siendo, por el contrario, que se apoyan en él para generar lo nuevo. Se le da importancia, por lo tanto, a la experiencia.

Antes de terminar este capítulo un tanto heterogéneo, pero tramado de manera lúcida, Jacob se refiere al problema de las suspicacias y temores que suscitan el potencial del ADN y las consecuencias de una manipulación genética que pudiera, en un momento dado, dar pie a la creación consciente o inconscientemente de monstruos humanos. Al respecto, Jacob dice lo siguiente:

Para producir un gen en gran cantidad, un gen humano, por ejemplo, es necesario insertarlo en el equipo genético de una bacteria, después cultivar a gran escala esta bacteria. Este trabajo ha provocado muchas pasiones y hostilidades. Se le ha acusado de atentar contra la calidad de vida y también de poner en peligro la vida humana. La ingeniería genética se ha convertido, así, en una de las principales causas de desconfianza hacia la biología. Junto con otras investigaciones - estudios sobre el feto, dominio de su comportamiento, psicocirugía o clonación de políticos - se ha acusado al trabajo en el ADN recombinante de dar a los biólogos el poder de deteriorar el cuerpo y el espíritu humanos. Es verdad que las innovaciones científicas pueden servir tanto para lo mejor como para lo peor, son fuente de desgracia como de beneficios. Pero lo que mata y lo que sirve no es la ciencia, son los intereses y la ideología. Como se dijo en el prólogo, a pesar del doctor Frankenstein y del doctor Strangelove, las masacres de la historia han sido ocasionadas más por curas y políticos que por científicos. Y el mal no viene solamente de la situación en que se utiliza la ciencia con fines destructivos. También puede ser una consecuencia lejana e imprevisible de acciones emprendidas por el bien de la humanidad (pp. 70-71).

En este sentido, si bien es acertado lo que dice Jacob, queda pendiente la cuestión de la responsabilidad social y la ética del científico o del hombre de ciencia. ¿Hasta dónde debe operar con libertad absoluta?, ¿acaso, como ser humano, no tiene en esencia las mismas responsabilidades sociales que los demás? Podría decirse que por su posición privilegiada en la sociedad de la que surge y en la cual opera, precisamente por su mayor acceso al conocimiento en comparación con el resto de sus conciudadanos (y demás miembros de la especie Homo sapiens, en una dimensión universal), el hombre de ciencia adquiere o se sitúa en un nivel especial de responsabilidad social, de la cual debe estar consciente, así como en la mejor disposición de compartir sus conocimientos no sólo con sus colegas, sino con la población en general, y de rendir cuentas e informar sobre los alcances, consecuencias y peligros que pueda haber para la humanidad, derivados de su conducta como científico.

Jacob se refiere luego a las pinturas de El Bosco (Hieronimus Bosch), en las que este último ilustró escenas pseudohumanas con la presencia de monstruos que parecen haber sido producto precisamente de una manipulación genética (y, ¡esto en el siglo XVI!). Así, Jacob agrega que, "[t]ales híbridos implican, en primer lugar, una dislocación del cuerpo y, después, un reacomodo de los pedazos. Como si para provocar la angustia, Bosch hubiese opuesto el desorden de un antimundo a la armonía de nuestro mundo" (p. 72).

Termina Jacob este capítulo con un reclamo sobre las quejas que expresan quienes más se asustan por los alcances de la ciencia y, sobre todo, por sus resultados racionales cuando éstos ponen en entredicho la validez y persistencia de los mitos sobrenaturales y metafísicos para explicar los fenómenos del mundo real, especialmente aquellos relacionados con el ser humano y su conducta. Jacob celebra con entusiasmo el potencial biológico, genético, celular y bioquímico del Homo sapiens, atribuyéndole a esa base fisiológica el poder del hombre para 
movilizarse, actuar en sociedad y relacionarse con sus congéneres, y así dice al respecto:

[Les] [r] esulta imperdonable [a los místicos] que se conciba al ser humano como un proceso que, por fusión de un espermatozoide y un óvulo, da inicio a la división de la célula-huevo, la cual se convierte en dos, después en cuatro, hasta formar una pequeña bola, más tarde una pequeña bolsa. Y después, en alguna parte de este pequeño cuerpo en crecimiento se diferencian algunas células que se multiplican hasta formar una masa de decenas de miles de millones de células nerviosas. Es gracias a esta célula que es posible aprender a hablar, a leer, a escribir y a contar. Y es gracias a esta célula que es posible tocar el piano, atravesar una calle sin que nos atropellen o dar una conferencia al otro extremo del mundo. Todas estas capacidades están contenidas en nuestra pequeña masa de células, toda la gramática, la sintaxis, la geometría, la música. Pero no tenemos la menor idea sobre la manera en que todo esto se construye. Para mí, ésta es la historia más sorprendente que podemos narrar en este mundo (p. 72).

La perplejidad de Jacob ante lo que él ve como una incógnita es sorprendente. Parece olvidar que la respuesta se encuentra precisamente en su propia alusión al proceso de aprendizaje, o a lo que los antropólogos llaman endoculturación. Si Jacob leyera los planteamientos de los antropólogos culturales, podría entender la respuesta a la incógnita planteada y que tanto le inquieta al final de su capítulo. Se podría advertir así tanto el punto de quiebre entre la evolución biológica del Homo sapiens al iniciar su proceso de adquisición y elaboración de la cultura, como la función de esta misma como mecanismo extrasomático (o superorgánico, como lo llamó Alfred Kroeber [1963: 61-63] hace mucho tiempo), que lo separó definitivamente del resto de las especies animales, aun cuando comparta con ellas una constitución genética semejante. Esas células nerviosas a las que se refiere Jacob y que él considera como responsables del aprendizaje no operan en el vacío, ni es suficiente que reaccionen al interior del organismo por mecanismos puramente combinatorios de las sustancias químicas existentes en el medio natural y que interaccionan con el organismo. Requieren también del estímulo exterior, que les proporciona la interacción social entre los seres humanos con su desenvolvimiento creativo, de formas materiales de vida, simbó- licas y ceremoniales, así como de todo aquello que constituye el estilo de vida de cada uno y de todos los grupos humanos en su conjunto, esto es, la cultura, en su sentido antropológico, que, a su vez, incide, modifica y condiciona (que no determina) la conducta humana 5 .

\section{TIEMPO, EVOLUCIÓNY CULTURA}

De manera muy ingeniosa, Jacob conduce al lector hacia el punto final de su libro, en el que destaca la importancia de la cultura en relación con la continuidad de la especie Homo sapiens. Sin embargo, para ello acude primero, y como punto de partida de su tercer capítulo, denominado "El tiempo y la invención del futuro", precisamente al análisis de la evolución orgánica que lleva al cerebro humano a descubrir la noción del tiempo como una noción que le permite separarse del resto de las especies y, cómo una vez adquirida esa capacidad, los seres humanos tie-

\footnotetext{
${ }^{5}$ Cabe aclarar en este punto que el planteamiento de Jacob resulta ser valioso precisamente porque no se presta a una interpretación excesivamente biologista ni racista, como las de algunos etólogos y sociobiólogos cuyos planteamientos se acercan al racismo cuando explican la conducta humana sólo sobre bases biológicas, orgánicas, excluyendo la base cultural. A pesar de los esfuerzos constantes de los antropólogos físicos para explicar de manera contundente la falta de validez científica de los planteamientos racistas, quienes los proponen y defienden no cesan de hacerlo periódicamente. Desde los famosos debates entre etnólogos antiesclavistas y pseudoantropólogos defensores de la esclavitud en la Inglaterra y los Estados Unidos durante el siglo XIX, hasta los casos más recientes como el del libro La curva de campana y el de la pugna entre evolucionistas y creacionistas. Como es sabido, Richard J. Herrnstein y Charles Murray, autores de la obra La curva de campana, pretendían demostrar la inferioridad racial de los afroamericanos en Estados Unidos, con el fin de que se suspendiera, por considerarla inútil, la asignación de recursos financieros a los programas educativos a favor de dicho sector de la población estadounidense. Afortunadamente, el esfuerzo de un grupo de eminentes biólogos, antropólogos físicos, antropólogos culturales y sociólogos, encabezados por el paleontólogo Stephen Jay Gould, logró desacreditar esa obra notoriamente racista, demostrando irrefutablemente el cúmulo de inconsistencias, falacias y manipulaciones de la información utilizada, tanto estadística como documental, con que los autores habían tratado de demostrar "científicamente" la validez de sus argumentos. Sobre los debates entre etnólogos y antropólogos en torno a la esclavitud, véase Alcántara Ferrer, 1986. Sobre la refutación al libro La curva de campana, véase Fraser, 1995. Y sobre el debate reciente entre evolucionistas y creacionistas, la literatura disponible es abundante, pero por lo pronto sólo se sugiere el diálogo más reciente entre dos defen-
} sores del evolucionismo: Krauss y Dawkins, 2007. 


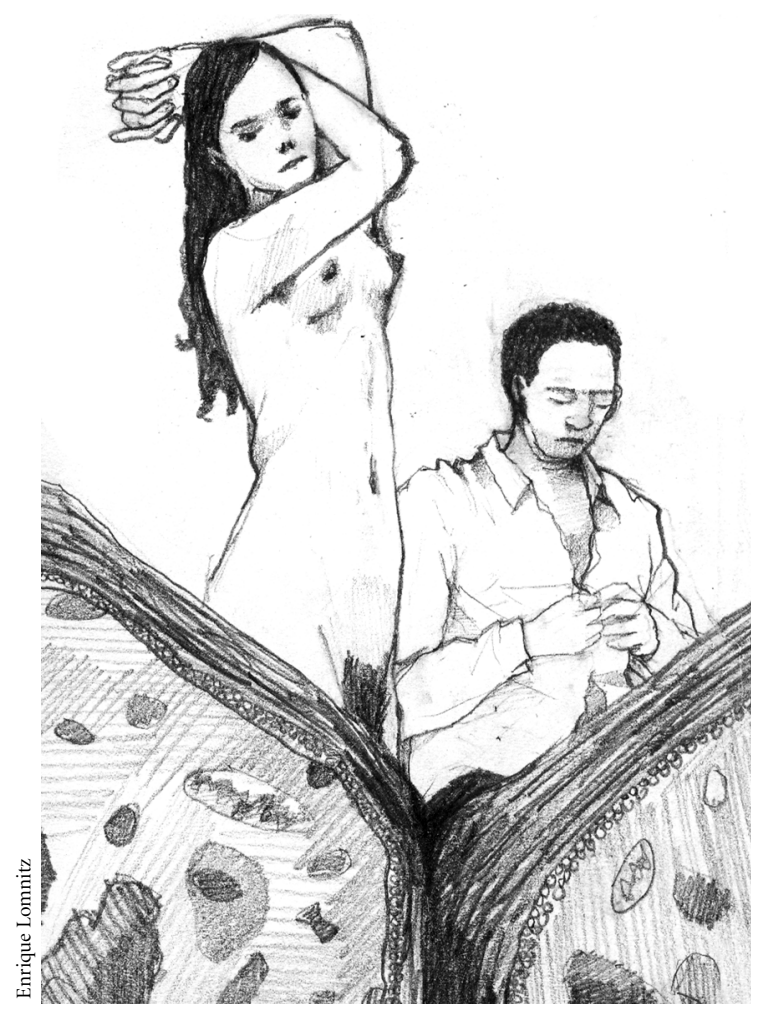

nen la aptitud de proyectarse del pasado y el presente hacia el futuro. Jacob da a entender, entonces, la habilidad del ser humano para imaginar el futuro como un proyecto a realizar y como metas concretas a lograr.

Jacob empieza explicando los mecanismos de protección de la supervivencia humana por medio del proceso de inmunización que se desarrolla en el propio organismo ante la inevitable llegada de la senectud. Así, dice al respecto:

El sistema genético y el sistema inmunológico funcionan, entonces, como dos memorias que registran el paso de la especie y el paso del individuo respectivamente. Pero un ser vivo no es sólo el último eslabón de una cadena ininterrumpida de organismos. La vida es un proceso que no se limita a registrar el pasado, sino que se dirige también hacia el futuro. Parece ser que el sistema nervioso surgió como un aparato que coordina el comportamiento de diversas células en los organismos multicelulares; después, se convirtió en una máquina que registra ciertos eventos de la vida del individuo y, finalmente, adquirió la capacidad de inventar el futuro (p. 80).
Enseguida, Jacob explica lúcidamente el mecanismo que permite la supervivencia del ser vivo. Y cómo, para lograrlo, el organismo requiere acumular y procesar tres elementos fundamentales, imprescindibles: materia, energía e información: "Los seres vivos no pueden sobrevivir, crecer y multiplicarse más que gracias a un flujo incesante de materia, de energía y de información" (ibid.).

De ahí la importancia de la relación de los seres vivos con el medio en el que sobreviven, tanto natural como cultural. Para eso, el desarrollo de los órganos sensoriales como el de la vista, el olfato, la audición, fue clave para el registro de la información que les proporciona a los seres vivos el medio ambiente que les rodea. Es así que, "[p]ercibir ciertos aspectos de la realidad es una exigencia biológica”, dice Jacob, resumiendo la importancia de recabar la información necesaria. Y agrega que:

\section{El mundo exterior, cuya "realidad" conocemos de manera intuitiva, parece ser, por ende, una creación del sistema ner- vioso; en cierto sentido es un mundo posible, un modelo que permite al organismo tratar la masa de información recibida y hacerla útil para la vida cotidiana (p. 82).}

Cabe señalar aquí la importancia de una realidad imprescindible: las vivencias, suscitadas por la conjugación de factores externos (combinaciones armoniosas de luces y sonidos, naturales o reproducidos por el propio ser humano, todo aquello que permite desarrollar el sentido de la estética, tanto individual como colectivo, y que podría considerarse que resulta ser imprescindible para la supervivencia mental del hombre). ¿Cuánto de lo que es producto de una cultura determinada llega a trascender su propio espacio generativo y adquiere una dimensión universal? La tecnología, por su carácter eminentemente práctico, es un ejemplo. Pero otro - tal vez más importante aún - es el de las artes, tanto plásticas como auditivas, además de la literatura, cuando alcanzan niveles de excelencia.

Jacob se refiere enseguida a la noción del tiempo como un elemento significativo percibido por el ser humano y elaborado en su cerebro, a diferencia de las otras especies que, aparentemente, carecen de dicha noción. La capacidad que desarrolló el Homo sapiens para percibir sensorialmente el universo que le rodea le permitió in- 
corporar poco a poco una representación objetiva de ese mundo.

Jacob lo atribuye al hecho de que los mamíferos pudieran tener una existencia diurna, una vez que desaparecieron especies muy depredadoras - como "los reptiles gigantes-, para lo cual su sistema visual estaba mejor dotado que el de esas otras especies. Esto,

[...] incluye la visión en color y los analizadores colocados en el cerebro y no en la retina. Información visual e información auditiva pudieron integrarse gracias a un código espacial y temporal único que permitía atribuir el origen de estímulos luminosos y sonoros a fuentes comunes, a objetos que persisten en el tiempo y en el espacio [...] Este cerebro puede, en efecto, conservar la identificación de un objeto a pesar de que la percepción se modifica sin cesar en el tiempo y en el espacio (pp. 83-84).

En otras palabras, Jacob se refiere a la capacidad del cerebro para guardar en la memoria las percepciones de los objetos, lo que genera la noción del tiempo: "Además, al estar asegurada la permanencia de estos objetos en el tiempo, su representación podía ser memorizada" (p. 84).

Jacob explica enseguida cómo se desarrolló la facultad de simbolizar o de elaborar símbolos y, por lo tanto, de forjar el lenguaje:

Por otro lado, combinando la percepción auditiva de secuencias temporales con ciertos cambios del aparato sensomotriz de la voz, fue posible simbolizar y codificar esta representación cognitiva de manera enteramente nueva. Desde esta perspectiva, si el lenguaje sirvió como sistema de comunicación entre individuos — según piensan muchos lingüistas-, es del todo secundario. Su primera función parece haber sido más bien, como en las etapas evolutivas que han acompañado a la aparición de los primeros mamíferos, la representación de una realidad más fina y más rica, una manera de procesar más información de manera más eficaz" (pp. 84-85).

Lo que Jacob destaca es nada menos que el origen de la cultura en el sentido antropológico o, por lo menos, de su dimensión simbólica. Sin embargo, es necesario recordar que esta idea ya había sido planteada, también en forma lúcida, por Gordon Childe en su otra obra clásica, What Happened in History (1964 [1942]):
En las sociedades humanas la instrucción es por precepto así como por el ejemplo. Las sociedades humanas han inventado gradualmente herramientas para la comunicación entre sus miembros. Al hacerlo, han descubierto un nuevo tipo de equipamiento al cual se le puede denominar convenientemente espiritual [mental].

Debido a la estructura de la laringe, los músculos de la lengua y otros órganos de los seres humanos, compartidos con algunas otras criaturas, son capaces de emitir una gran variedad de ruidos a los que técnicamente se les llama sonidos articulados. Al vivir en sociedades y poseer cerebros en expansión, los hombres han sido capaces de atribuir a estos sonidos significados convencionales. Por común acuerdo, los sonidos se convierten en palabras, señales para la acción y símbolos para objetos y sucesos que les sean familiares a otros miembros del grupo. (Nótese, de paso, que a los gestos también se les puede atribuir significados de la misma manera, aunque menos convenientemente). En este sentido, los trinos de los pájaros y los balidos de las ovejas tienen significados; al escuchar la señal de los miembros del rebaño, se actúa de manera adecuada. Para ellos esto significa por lo menos la acción [o la necesidad de entrar en acción] y genera una respuesta adecuada en la conducta de las criaturas. Entre los hombres, la palabra hablada (y desde luego, también los gestos) cumple la misma función, pero a una escala extraordinariamente más rica (p. 17, trad. del autor al español).

El lenguaje como sistema de codificación simbólica le permite al ser humano construir o elaborar una visión del futuro mediante la planeación de acciones posibles o la posibilidad de organizar la acción con fines determinados. Así, dice Jacob:

[...] traducir un mundo visual y auditivo de manera que los objetos y eventos son designados con precisión y reconocidos semanas o años más tarde [o sea, memorizados], exige un sistema de codificación mucho más elaborado. Lo que da al lenguaje su carácter único, según parece, no es tanto servir para comunicar directivas para la acción, sino permitir la simbolización, la evocación de imágenes cognitivas [...] [Así] Permite la creación mental de mundos posibles (p. 85).

Sin embargo, esa creación de "mundos posibles" parte de la noción de que se vive "en un mundo 'real' que es construido por su cerebro [del ser humano] con la información dada por los sentidos y el lenguaje”. Y, agrega Jacob, que "[e]ste mundo real es el escenario en el que se 
desarrollan los acontecimientos de la vida". Pasa luego a considerar la función de la conciencia o el proceso de adquisición de conciencia, la cual Jacob explica como "la percepción de sí mismo en tanto que 'objeto' colocado en el centro mismo de la realidad". Jacob considera que es difícil precisar en qué momento de la evolución el ser humano advirtió por primera vez la conciencia de sí mismo o estuvo consciente de su propio ser (ibid.).

Jacob descarta la explicación epistemológica que se sustentaba en la introspección y, según la cual, "los eventos mentales no podían ser de la misma naturaleza que los físicos". Por el contrario, aclara que:

[...] conferir una suerte de psique a las partículas que constituyen la materia no arregla nada. Por tanto, no podemos evitar concluir que el "espíritu" es un producto de la organización del cerebro tanto como la vida es un producto de la organización de moléculas (p. 86).

Esta afirmación tan contundente le permite a Jacob coincidir con los antropólogos, en especial con los paleontólogos en los cuales se apoya y reconoce cuando éstos trazan la evolución del cerebro de los homínidos como resultado de la interacción entre:

[...] la recolección de informaciones sobre el mundo exterior y la representación de la realidad, como factor de presión selectiva persistente a todo lo largo de la evolución de los mamíferos, incluyendo a los homínidos" (p. 87).

Jacob se acerca enseguida a la noción antropológica de cultura, aunque sólo lo logra parcialmente, ya que la constriñe a:

[...] ciertas actividades humanas, las artes, la producción de mitos o de las ciencias naturales, como desarrollos culturales en la misma dirección [...] Todas operan recombinando fragmentos de la realidad para crear nuevas estructuras, nuevas situaciones, nuevas ideas [en una palabra, para generar innovaciones]. Y un cambio en la representación del mundo puede traer consigo un cambio en el mundo físico mismo, como lo muestran los efectos del desarrollo tecnológico (ibid.).

Así, Jacob llega finalmente a la noción antropológica más acabada de cultura, repitiendo en cierta manera lo que ya han señalado con claridad y precisión numerosos antropólogos, aunque Jacob no cita a ninguno de ellos. "Casi todo lo que caracteriza a la humanidad — dice Jacob- se resume en la palabra cultura” (ibid.). Lo cual es simplemente otra manera de decir lo que han planteado constantemente los antropólogos culturales, o sea, que todos los seres humanos tienen cultura y que ésta es lo que distingue definitivamente a la especie Homo sapiens del resto de las especies (Boas, Kroeber, Herskovits, Murdock, Malinowski, Harris, etc. $)^{6}$.

Para los antropólogos no es nada nuevo lo que dice Jacob al referirse a la cultura en el sentido de que:

La transmisión de rasgos culturales tiene una analogía un tanto superficial con la transmisión de los rasgos biológicos, a menudo es designada con el nombre de "herencia cultural". El principal parecido entre los dos sistemas es su tendencia natural a conservar manteniendo la posibilidad de cambio y, en consecuencia, haciendo posible la evolución. Pero los rasgos culturales se propagan por un mecanismo de tipo lamarckiano [por adquisición y no por herencia genética]. La evolución cultural puede, por ende, producirse a una velocidad muy superior a la de la evolución biológica. Por su biología, el ser humano del siglo XX no parece diferente al que vivió hace treinta mil o cuarenta mil años. En cambio, el mundo cultural, social y tecnológico en el que muere un ser humano a finales del siglo XX no tiene casi nada en común con aquél en el que nació (ibid.).

Esto último es, evidentemente, una exageración de Jacob para subrayar esa velocidad del cambio cultural que, si bien es ciertamente muy acelerada a finales del siglo XX - tanto que se puede calificar dicho proceso como revolucionario-, sin embargo, no deja de haber una relativa continuidad en la evolución de la cultura. Por ello, debe precisarse que algunos de sus componentes cambian más

\footnotetext{
${ }^{6}$ Además de los ya mencionados Alfred Kroeber y Leslie White, es pertinente volver a consultar a otros clásicos de la antropología cultural, algunas de cuyas aportaciones siguen vigentes, como Boas, 1940; Herskovits, 1967; Kluckhohn, 1949; Malinowski, 1944; Murdock, 1997; Harris, 1980 y, más recientemente, Kuper, 2001. La mención de todos estos antropólogos culturales se justifica como alternativa de consulta por sus enfoques y definiciones más coherentes en torno al concepto de cultura, en comparación con la confusión imperante en la actualidad sobre dicho concepto entre una gran parte de los antropólogos contemporáneos, algunos de los cuales, como los del grupo de Santa Fe en Nuevo México, Estados Unidos, han llegado al grado de poner en tela de juicio la utilidad del concepto de cultura en la antropología. Véase al respecto, entre otros, Abu-Lughod, 1995.
} 


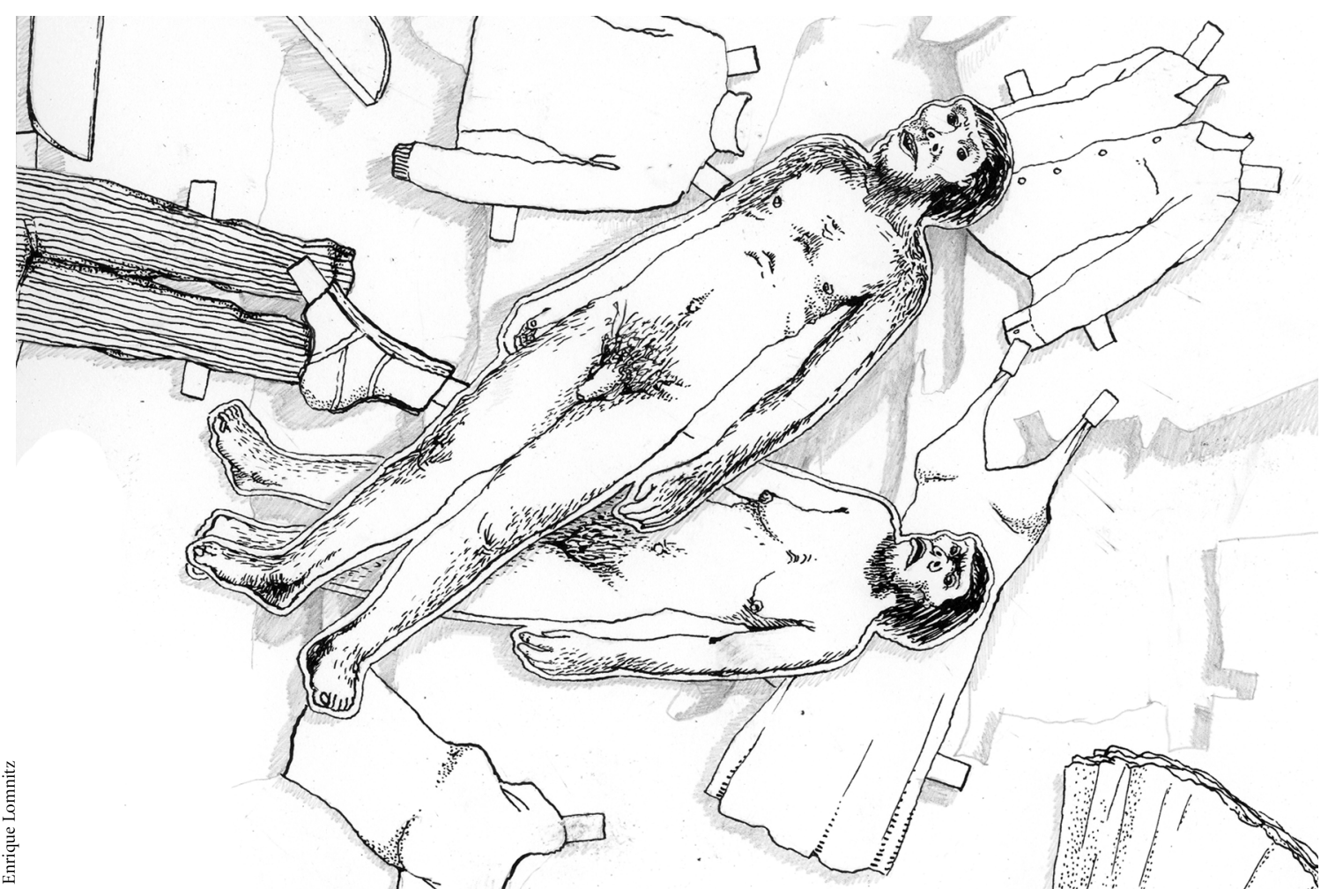

rápidamente que otros, en concreto los de la tecnología y la economía.

Jacob rechaza luego - y con acierto- la insistencia tan común en separar tajantemente lo biológico de lo cultural, cuando, según su parecer, hay una interdependencia innegable entre los dos. Explica que la razón de negar esa interdependencia es de orden político e ideológico (ibid.). Se refiere entonces a un tema que no sólo suele generar debates álgidos, sino oposición al hecho de que el ser humano sea producto de la evolución biológica. La explicación que aporta Jacob sobre la interacción entre lo genético y lo cultural en el ser humano es sumamente útil para zanjar esas discusiones a favor del argumento científico y no del metafísico.

Primero, Jacob señala con acierto un hecho social: el conflicto que se suscita cuando la ciencia permite poner en entredicho creencias populares muy arraigadas y sancionadas por grupos sociales específicos, que ven amenazada su hegemonía. Es entonces que "aumenta la manipu- lación y utilización de los datos aportados por la ciencia a los fines ideológicos y políticos" (p. 88).

En cuanto a la biología, Jacob explica cómo la discusión se centra en atribuir ciertas aptitudes de los seres humanos ya sea a la parte innata o a la adquirida, esto es, a la genética o a la cultura. Jacob aclara esta discusión explicando cómo se relacionan ambos factores:

En los organismos simples, el comportamiento está determinado de manera estricta por los genes. En los organismos más complejos, el programa genético se hace menos constreñido, más 'abierto', según la expresión de Ernst Mayr (37), en el sentido de que no describe en detalle los diferentes aspectos del comportamiento, sino que deja al organismo posibilidades de elección, le da una cierta posibilidad de respuesta y, en vez de imponerle instrucciones rígidas, le confiere potencialidades y capacidades. Esta apertura del programa genético aumenta en el curso de la evolución y culmina en la humanidad. Los cuarenta y seis cromosomas del ser humano le confieren toda una serie de aptitudes, físicas o mentales, que puede explotar y desarrollar de 
manera muy variada según el medio y la sociedad en la que crece y vive. El equipamiento genético le da al niño, por ejemplo, la capacidad de hablar, pero el niño aprende de su medio un cierto lenguaje y no cualquier otro. El comportamiento de un ser humano es moldeado, en todas sus características, por una incesante interacción de los genes y el medio (ibid.)

En otras palabras, esta explicación es equiparable a la de Malinowski sobre las necesidades biológicas humanas y su contraparte cultural para satisfacerlas (Malinowski, 1944).

Lo que no queda claro en esa explicación de Jacob es la razón por la que existe esa plasticidad o flexibilidad en los organismos más complejos como el ser humano. De hecho, este último no es el único mamífero que tiene esa facultad que le permite adquirir pautas de conducta por vía del aprendizaje y no por vía genética. En este sentido, la antropología permite explicar de manera acertada ese o esos mecanismos extrasomáticos que no sólo sirven para adquirir y transmitir cultura, sino para crearla, tal como lo plantearon Alfred Kroeber (1963) y Leslie White (1959a, 1959b), entre otros.

Jacob reduce el mecanismo de aprendizaje a la programación genética de que dispone cada individuo, por lo que se trata del mecanismo de operación, pero parece olvidar el de la interacción social, que es el que permite la asociación de individuos y que compartan afinidades en la conducta, con lo cual pueden llegar a fijar metas y objetivos de común acuerdo, que se traducen en acciones conjuntas motivadas por intereses compartidos y de convivencia. Estas acciones, que se inician con la asignación de significado, desarrollan la capacidad de crear símbolos —útiles para establecer la comunicación-, al igual que para la interpretación y explicación de las cosas, los hechos, las interacciones y los juicios mismos. Se desarrolla entonces la capacidad de pensar y razonar, de preguntar y responder satisfactoriamente, no sólo por mecanismos genéticos, celulares y biológicos, sino sociales y culturales propiamente dichos; todo ello se desarrolla de manera acumulativa a la vez que transformativa. En otras palabras, se aprende, como lo planteara Gordon Childe hace mucho tiempo, a satisfacer la curiosidad y, para ello, a indagar (1964 [1942]: 28). Jacob dice al respecto:
Como todo organismo vivo, el ser humano está genéticamente programado, pero está programado para aprender. La naturaleza nos ofrece todo un abanico de posibilidades en el momento del nacimiento. Lo que es actualizado se construye poco a poco durante la vida por la interacción con el medio (p. 93).

Jacob plantea luego con suma convicción una lección que proviene de la biología y que se refiere a la diversidad de los seres vivos, lo cual es sumamente positivo porque, según Jacob lo explica, es "uno de los principales motores de la evolución, un fenómeno natural sin el cual no estaríamos en este mundo" (ibid.). De lo biológico pasa a lo social y señala cómo a veces, en algunas sociedades, no se acepta fácilmente esa condición de la diversidad humana, tanto por quienes critican la existencia de un orden social injusto y pretenden que todos sean iguales, como por aquellos que pretenden que todos los individuos estén sujetos a un determinado orden social impuesto por un grupo hegemónico y no toleran las desviaciones fuera de ese orden. Jacob critica esas dos posiciones - a las que considera extremas-, así como el hecho de que pretendan manipular a la ciencia para justificar sus fines particulares, crítica que, en esencia, es correcta. Así, dice Jacob:
A pesar de ciertas afirmaciones, no es la ciencia la que de- termina a la política, sino la política la que deforma a la ciencia y hace mal uso de ésta para encontrar justificación y coartada. Por un singular equívoco, se confunden dos no- ciones que, sin embargo, son muy distintas: la identidad y la igualdad. Una se refiere a las cualidades físicas o men- tales de los individuos; la otra, a sus derechos sociales y jurídicos. La primera procede de la biología y de la educa- ción; la segunda, de la moral y la política. La igualdad no es un concepto biológico. No se puede decir que dos mo- léculas o dos células sean iguales, ni tampoco dos anima- les, como nos lo recordó George Orwell (pp. 93-94).

Finalmente, Jacob expresa un temor de la sociedad actual, muy compartido por quienes no advierten con claridad la condición plástica de la cultura y creen que la humanidad se dirige irremediablemente hacia una situación de homogeneidad cultural como resultado del proceso de industrialización. Jacob extrañamente cree que: 
Cada día disminuye esta extraordinaria variedad que han puesto los hombres en sus creencias, sus costumbres, sus instituciones. Mientras los pueblos se extinguen físicamente o mientras se transforman bajo la influencia del modelo que impone la civilización industrial, muchas culturas desaparecen. Si no queremos vivir en un mundo invadido por un modelo único de vida, por una sola cultura tecnológica y de lenguaje obtuso, es necesario tener mucho cuidado y usar de una mejor manera la imaginación (p. 95).

Jacob no parece advertir que la cultura, en su sentido antropológico, es sumamente compleja y plástica, y que así como desencadena procesos de aparente homogeneización en ciertos o algunos de sus componentes estructurales, así también genera complejos culturales nuevos que no necesariamente tienen que ser destructivos. Lo que esto implica es un reto a los seres humanos para que logren combinar eficazmente la continuidad cultural de aquello que sea útil y necesario, a pesar de las destrucciones que parecen suscitar de manera inevitable los procesos de cambio excesivamente acelerados. Jacob apela con acierto a la ciencia y a la imaginación del ser humano a la actualidad: la primera, porque le permite al hombre advertir y prever el futuro más o menos inmediato; y la segunda, porque lo capacita para escoger las soluciones más razonables. Así, Jacob termina su inspirador libro diciendo:

Pero los seres humanos tienen tanta necesidad de sueños como de realidades. Y es la esperanza lo que da sentido a la vida. La esperanza se funda en la posibilidad de transformar el mundo presente en un mundo posible que parece mejor (p. 96).

El libro de Jacob se suma entonces a esas obras que, de vez en cuando, como la lámpara de Diógenes, iluminan el camino hacia el conocimiento y permiten avanzar a pesar de los obstáculos, además de inspirar al lector para que contribuya a superarlos.

\section{Bibliografía}

Abu-Lughod, Lila, 1995, "Writing Against Culture", en Richard G. Fox (ed.), Recapturing Anthropology. Working in the Present, School of American Research Press, Santa Fe, pp. 137-162.

Alcántara Ferrer, Sergio, 1986, “Etnia o cultura? Un ensayo sobre su conceptualización”, Encuentro, vol. 3, núm. 4 (12), julio-septiembre, El Colegio de Jalisco, pp. 5-45.

Boas, Franz, 1940, Race, Language and Culture, The Macmillan Co., Nueva York.

Childe, V. Gordon, 1964 [1942], What Happened in History, Penguin Books, Midlesex. (Hay edición en español.)

__ 1970, Los orígenes de la civilización, Fondo de Cultura Económica, México. (La 1a ed. en inglés apareció bajo el título de Man Makes Himself, 1936.)

Clark, Graham, 1964, "Foreword", en V. Gordon Childe, What Happened in History, Penguin Books, Middlesex.

Erickson, Paul A. y Liam D. Murphy, 2003, A History of Anthropological Theory, Broadview Press Ltd., Peterborough, Ontario.

Fraser, Steven (ed.), 1995, The Bell Curve Wars, Basic Books, Nueva York.

Harris, Marvin, 1980, Cultural Materialism. The Struggle for a Science of Culture, Vintage Books, Nueva York.

Herskovits, Melville J., 1967, El hombre y sus obras, Fondo de Cultura Económica, México. (1ª ed. en inglés, 1948.)

Jacob, François, 2005, El juego de lo posible, Fondo de Cultura Económica, México. ( $1^{\text {a }}$ ed. en francés, 1981.)

Kluckhohn, Clyde, 1949, Mirror for Man. A Survey of Human Behavior and Social Attitudes, McGraw-Hill Book Co., Nueva York.

Krauss, Lawrence M. y Richard Dawkins, 2007, "Debate. Should Science Speak to Faith?", Scientific American, vol. 297, núm.1, julio, pp. 70-73.

Kroeber, Alfred L., 1963, Anthropology: Culture Patterns and Processes, Harcourt, Brace \& World, Inc., Harbinger Book, Nueva York.

Kuper, Adam, 2001, Cultura. La versión de los antropólogos, Paidós, Barcelona.

Malinowski, Bronislaw, 1944, A Scientific Theory of Culture and Other Essays, University of North Carolina Press, Chapel Hill.

Murdock, George Peter, 1997, Cultura y sociedad, Fondo de Cultura Económica, México. (1 $1^{a}$ ed. en inglés, 1965.)

Waal Malefijt, Annemarie de, 2001, Imágenes del hombre, Amorrortu, Buenos Aires.

White, Leslie A., 1959a, The Evolution of Culture. The Development of Civilization to the Fall of Rome, McGraw-Hill, Nueva York.

, 1959b, "The Concept of Culture", American Anthropologist, vol. 61, núm. 2, pp. 227-251. 